\title{
Archaeology versus Urban Development in Cartagena
}

\author{
Francisco Segado Vázquez and José Manuel Maciá Albendín.
}

Received 28 Apr 2015 Accepted 21 May 2015

\begin{abstract}
Archaeology has taught us what our origins are, but frequently it works in an independent way, avoiding any kind of collaboration with other disciplines such as Urban Development. Most often, archaeologists, managed by different government bodies, tend to work independently of urban planners. This system has led to archeologists getting the recognition for their discoveries while at the same time depriving society of the knowledge of the cities origin. As a consequence, urban development cannot fulfill its role. The fact that archeological and urban development projects are carried out separately is the main reason for the absence of any relationship between current town planning in the cities and old and buried urban planning. As a result, society is the loser in a battle in which there are no winners.
\end{abstract}

In Cartagena (Spain), Pedro A. San Martín (1921-2013), an architect, a member of the Department of Fine Arts of the Ministry of Culture, Local commissioner of Archaeological Excavations and Director of the Municipal Archaeological Museum of Cartagena, developed a multi-layered approach (technical and urban) in the pursuit of one central objective: the revaluation of the city in its entirety. He tried to be an architect among archaeologists, learning the methods and ways in which archaeologists worked, and also an archaeologist among architects, trying to explain to them how they had to coordinate their discoveries in order to achieve a viable relationship between the old and the new city in Cartagena. His efforts are a great example of how both disciplines should be combined.

Keywords - Archaeology, Urban Development, Tarragona, Mérida, Cartagena

\section{INTRODUCTION}

Many articles have been written about the coexistence of superimposed historical cities on the same urban fabric over the last decades. Most of them seem to have focused on different social, economic and archeological points of view, and have omitted, on many occasions, the most important discipline which should concern all of them: urban development. In fact, bearing in mind the definition of Urban Development "knowledge relating to the planning, development, reform and extension of buildings and spaces within urban areas" -, these spaces within urban areas do not refer to any particular time. Therefore, Urban Development can and should link the different ages in which cities have lived, and that entails recovering the true essence of the composition and origin of the cities.

This becomes even more obvious when government bodies tend to give more importance to the evaluations, considerations and assessments that focus on the order in which they appear rather than on the elements that should be highlighted as the way to establish the real relationship between old and new urban plans. The chronological order of the different actions seems to be more important than the global vision, and, hence, most often, the figure of the urban architect is the last one to be involved in the process and must assume the previous actions of other professionals who have looked after their own interests from the perspective of their own discipline. In most occasions it may be too late to recover the old plans under the new cities.

Usually, when any kind of archaeological discovery is made, archaeologists are called in order to carry out the necessary works for an appraisal of the findings. However, urban architects are called when they have to accommodate, within a global vision, the archeological discovery with the current urban plans and demonstrate how this discovery can affect the development of the city. A lot of dispersed remains tend to take up independent areas of the cities without any kind of connection.

Due to this, in most cases there is a lack of coordination among the different government bodies to promote the interdisciplinary team work that would allow laying the foundations for the research aimed at the coexistence of two cities instead of their overlapping.

We need to understand what is failing in order to know how to correct it. The present article tries to analyze old methods and its consequences, in order to define a modus operandi in dealing with archaeological remains.

Therefore, the key findings of this research must be:

- Define cities whose characteristics are similar to those of the Roman Age.

- Define patterns of urban projects and plans in cities of similar characteristics.

- Set out the legal and urban plans of action.

- Research the involvement of architects in archaeological excavations in the studied cities.

- Draw conclusions regarding the results and consequences of the involvement of architects in the archaeological works in the studied cities. 


\section{HISTORICAL BACKGROUND}

For a long time, Spain did not develop any plan to preserve its cultural heritage. Archaeological findings were preserved by local government bodies that would build a "museum" around or over the place where the discovery had been made. Urban development was the way to regenerate and shape the city but not its history and culture, and it did not have any influence over archaeology. It did not seem necessary to establish the relationship of these disciplines in the city.

In 1985, the Ministry of Culture and the General Directorate of Fine Arts published "Archaeology of modern cities superimposed on old ones, Zaragoza 1983"[1], which is one of the first studies about the conflicts that were starting to take form, regarding the way of recovering the origins. The fact that it coincided with the publication of the Law 16/1985, of June 25, on the Historical Spanish Heritage is not a mere coincidence and reveals a shift in the way of addressing and highlighting recovery projects. The aforementioned publication includes the article "Cartagena: Conservation of archaeological urban sites in the old town", written by Pedro A. San Martín, which already deals with the issues affecting the city on which we will focus later, an example of which is the works carried out with the Roman remains.

In the course of the European Seminar on the Management of Historical City Centers, that took place in the city of Granada (Spain) [2] in 2000, the sensitivity about the question of the relationship between archaeology and urban development is revealed in different presentations. One of them stands out: "The city inside the city: the integration of heritage management in modern urban development" [3] written by Siri Myrvoll, Secretary General of the Organization of World heritage Cities (OCPM) and Director of the Heritage Management of Bergen (Norway). Focused on the issues of the city of Bergen, it raises similar issues to the ones raised in Spain and more countries all around the world. One of these local scenes corresponds to the presentation "The patrimonial management in a city superposed to an archaeological site: the model of Merida" [4] written by Pedro Mateos, General Manager of the Consortium of the Monumental City of Merida (Spain).

Further on, in 2004, during the period of maximum exploitation of the urban development and real-estate resources in our country, in the III International Congress about Exhibition of Archaeological Sites, a presentation is published on the Project APPEAR (Accessibility Projects Sustainable Preservation and Enhancement of urban sub-soil Archaeological Remains) [5], developed in the period 20032005. This project presents a few proposals of standardization in urban development action in order to highlight the heritage protected under different coordinated and related disciplines. It is funded by the European Commission (Contract EVK4-200200091) and is included in the programme "The city of tomorrow and the Cultural Heritage". It is an innovative proposal aimed at a specific goal, a global action, although it may be considered insufficient.

The Project proposes as a final product, a guide of good practices regarding the action on archaeological sites or heritage assets, but it is probably based on a wrong approach. From an initial catalogue of different sites or buildings of historical interest in different cities, it proposes the steps to follow in the process but forgets the special characteristics of each city. Any proposal aimed at highlighting only specific elements - instead of the city as a whole - can only be detrimental, since it would remove all the elements that interrelate and interlink; the elements that give sense to the city.

The fact that it has to be the European Commission who has to intervene in this situation to try to regulate the action turns out to be enlightening enough, after two decades of the first approaches. Although, far from using a regulatory framework, it carries out this task through studies and proposals of multidisciplinary teams leaving the implementation in the hands of the different government bodies.

It seems to be impossible to understand the layout of a Roman city taking into account only the different findings of daily items of the time or independent buildings. All these elements must be considered from the outset as an inseparable part of the whole to which it gives sense.

\section{CURRENT SITUATION}

In Spain we find many significant examples of action aimed at highlighting the Archaeological Heritage, although its final purpose moves away from the objective of linking and integrating two cities into one.

Outstanding cases on which proposals have been made and solutions implemented are the Castle of San Jorge and the Encarnación in Seville [6], where it was proposed that archaeological discoveries were to be exhibited in the place of its finding, as a new kind of proposal in the appraisal of the heritage; the Square of the Orphans and the Square of Martos Door in Jaén [7], where importance was given to the different archaeological aspects and the creation of new artistic resources in the squares of the city center; the Foro and the Theatre museums, and the museums of the Thermal baths and the Fluvial Port in Zaragoza [8] (rules were established leading to the selection of the themes of the four museums that form the Caesar Augusta Route, with the on-site evaluation of remains and the reviving of the buildings); the surroundings of the Roman Theatre in Cádiz [9], which is the paradigm of the current thesis between the rescue of the documentary value of the archaeological findings, opposed to the defense of the current urban planning of the present city. There are some examples of partial, and probably timid, action, where we can detect a lack of urban development plans. Local, regional and national authorities considered necessary the self-management of the companies and foundations that were created at the same time as these museums or archaeological sites, so that they could justify and pay off the investment understood as an economic and touristic resource, but they were unable to value the long-term investment of the city sustainability.

If we make a comparative analysis of different Spanish cities we will be able to understand the current situation that has led to such disparate actions under the same regulatory framework. This fact reveals the lack of a standardized procedure to highlight the historical heritage by linking it to the city development.

Let us take as elements of reflection and comparative analysis Tarragona and Merida, contemporary, distant and with 
different configurations at present, but with a meticulous museum work. The relationship between both cities is also understood in military terms. While both were military cities in Roman times, the colony of Tarraco was considered to be a billeting city and Emeritus August became a destination for retired soldiers.

\section{COEXISTENCE IN TARRAGONA}

Being one of the Spanish cities with a greatest legacy of the Roman times - given its importance as a colony in the imperial epoch - we can use the archaeological and urban development works carried out in this city to understand the coexistence of both disciplines.

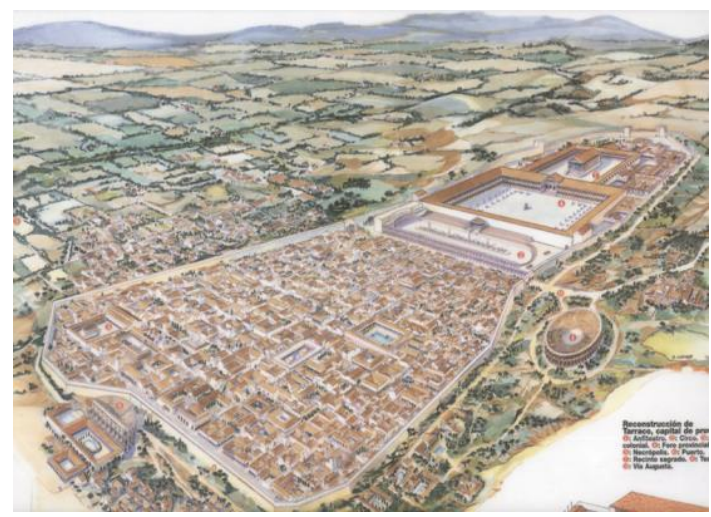

Figure 1. Recreation of the colony of Tarraco.

"Tarragona, in Latin Tarraco, provides us with a memorable example of those cities that after having astonished the universe with their brilliance, their expansion and their power disappear in an instant and only preserve a famous name and a sterile recollection of their past glory. This city, one of the most notable of the Roman Empire, the first one of the Hispanic provinces, headquarters of the praetors, center of power of the republic of Rome is reduced today to an enclosure of three scanty quarters of league of circumference and to a population from 9 to 10.000 souls, very simple buildings and a condition not far from poverty " [11].

In Roman times, Tarraco was a billeting city of Roman troops in the different warlike periods and the governors' residence city together with Cartago Nova. Both were the capitals of the provinces of Hispania Citerior and Hispania Ulterior. Two coastal cities that shared similar findings and urban development might have been an example of similar actions, since the importance that both acquired over the centuries was comparable, in spite of the fact that currently Tarragona has half the population in the town census.

Following three steps we can make a simple process to understand how history influenced in the development of the city if it really happened.

\section{A. Archaeological remains.}

The Roman ruins of Tarraco were designated a World Heritage Site by UNESCO in 2000. The most important historic elements which have been restored are the Roman walls, the Amphitheatre, the Roman circus, the Pretorium -
Tower, the Forum, the Necropolis, the palace of Augustus, and the Arch of Sura or Arch of Bara.

\section{B. Overlapped cities.}

If we make a simple analysis on a current map of this city, we can describe a well-defined historical center surrounded by a clear enlargement structure, approved in 1857 under the project of the Engineer Commander Ángel Del Romero [12]. It consists of two plots, well defined from a town planning perspective, with a clear pattern where the defining axes of the Roman city can by no means be distinguished, beyond the delimiting of the walls.

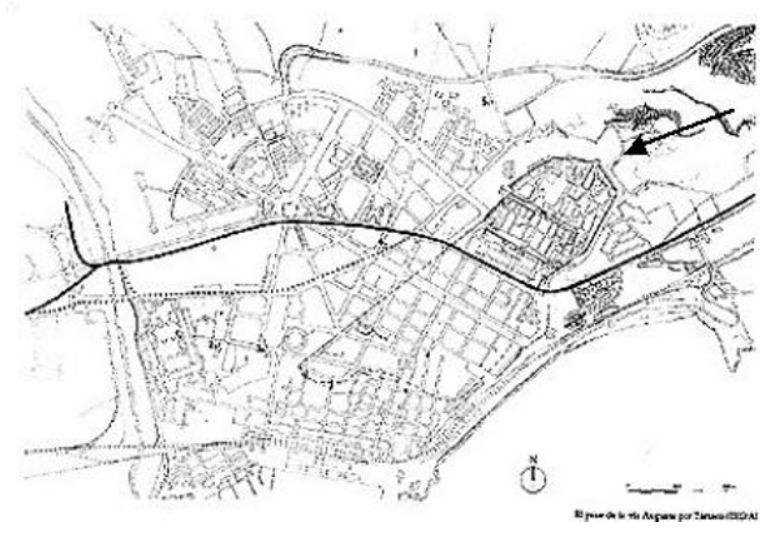

Figure 2. Map of the city of Tarragona.

If we make a comparison between the size and dispersion of the archaeological remains on the urban net and the current urban situation we cannot find any relationship between both plans. The current urban plan does not try to link the remains to the areas of expansion and the Local Heritage is a group of disperse elements which cannot be connected following any axis or itineraries. It is a sign of the lack of urban continuation trough different ages.

\section{Urban plans and laws.}

Historically, the declaration of the whole city as Historical Artistic Set (D 652/1966, BOE 22/III/1966) takes place in 1966, defining three areas: the historical center, entirely protected; a respected area, with archaeological plans and control of heights and volumes of the buildings to preserve the urban silhouette; and a few zones of enlargement merely subject to archaeological control. The above mentioned gradation emphasizes the differentiation of zones instead of pursuing global and joint action inside the whole city.

"The declaration of 1966 left in the hands of the Archaeological Provincial Museum the accomplishment of the excavations in those cases foreseen by the Law. In 1967, P.M. Berges, took charge of the direction of the MAP until 1978. Under Berges's direction different reforms in the museum and important excavations were carried out in the villa dels Munts, the square of the Foro, the Antigua Audiencia and the Roman Theatre. In these years, the MAP had limited economic and human resources to carry out the archaeological interventions imposed by the law. Furthermore, apart from a few exceptional findings, the Museum lacked effective legal instruments of pressure against the private builders or the different government bodies. In spite of it, they managed to achieve diverse and very meritorious interventions, but certainly there 
did not exist any foreseen relationship between the urban development studies of the archaeological heritage and the planning and development of the city and its environment" [13].

Clearly, the urban development approaches of the city are older than the archaeological ones, which date back only a few decades ago, but it seems strange to see how archaeology has removed the concept of urban development instead of trying to integrate it. Attention is paid to small spots in the city rather than to the whole city; some parts of it acquire more importance than the whole.

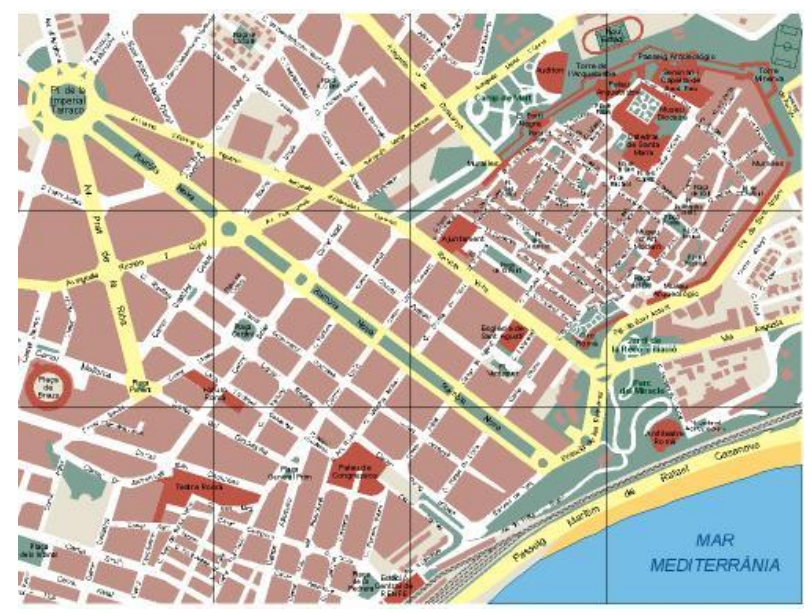

Figure 3. Tourist map of the city of Tarragona.

The findings made of 48 Roman villas on the ancient archaeological landscape in the Ager Tarraconensis in 2005 are further evidence of the situation. This project, promoted by the Institut Català d'Arqueologia Clàssica (ICAC) and the Institut d'Estudis Catalans (IEC) and entitled 'Study of the archaeological ancient landscape in the Ager Tarraconensis (to the right of the river Francolí)', gathered a team of 20 professionals, mainly archeologists and geologists forgetting again the figure of the architect and his or her importance for the urban development study of the coexistence of urban superposed plots of different times.

\section{COEXISTENCE IN MÉRIDA}

"The Lusitania's capital, Emeritus August, founded by Emperor Augusto in 25 B.C., a few years after the beginning of the Cantabrian Wars as part of his legacy to settle the war veterans, is one of the Hispanic cities that offers most information to study a topic that has become fashionable in the research of the Ancient World today: that of the relationship between urban development and religion" [14]. In his "Studies on the archaeological set of Emeritus August" on the city of Merida (Spain), archeologist Jose Maria Blázquez Martínez emphasizes the importance he attaches to urban development as a shaping element of the city.

\section{A. Archaeological remains.}

Among the restored remaining Roman monuments that we must point out are the Roman bridge (over the Guadiana River that is still used by pedestrians), the Roman walls and the court houses Roman mosaics.
Other important remains are the Forum, including the Temple of Diana, the Roman Provincial Forum, the Arch of Trajan, and of course, the remains of the Circus Maximus (1st century BC), one of the best preserved Roman circus buildings, Aqueduct of Miracles, the patrician villa called the Villa Mitreo, with precious mosaic pavements, the Proserpina Dam and the Cornalvo Dam, two Roman reservoirs still in use, the Amphitheatre, and the Roman theatre.

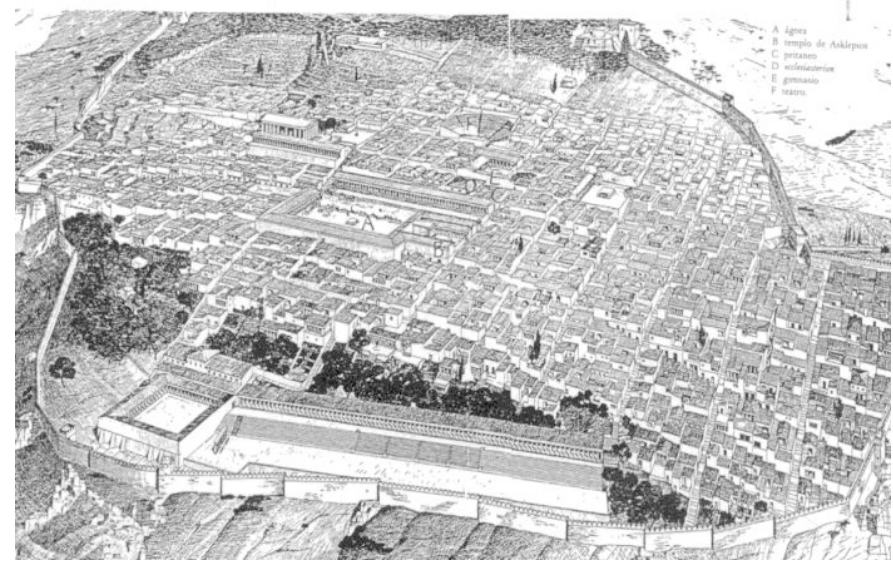

Figure 4. Recreation of Emérita Augusta colony.

\section{B. Overlapped cities.}

A plan of Merida where we can locate the different sites under study or highlighted gives us a vision of seemingly unconnected elements spread around this urban network, as if somebody had made a hole in order to avoid the image of a degraded city instead of showing the relationship between each element found.

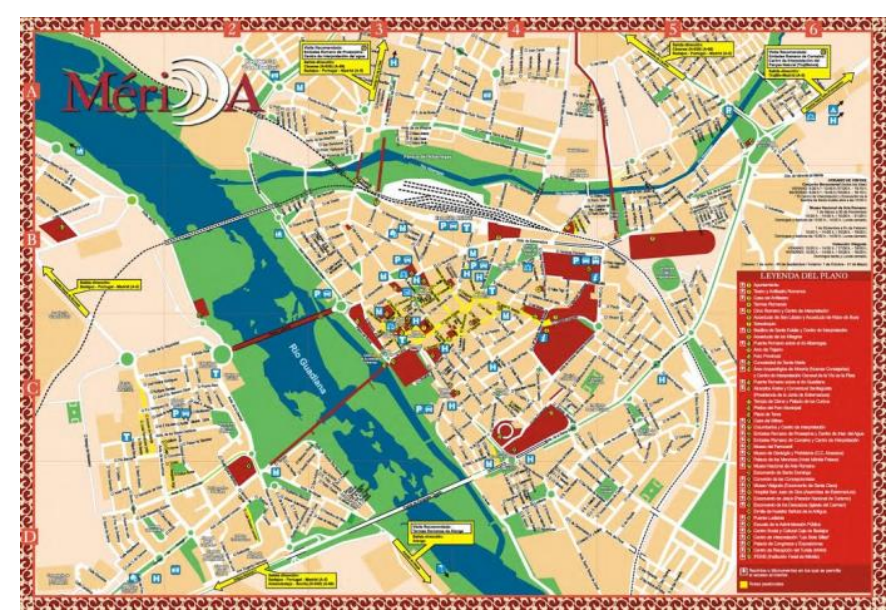

Figure 5. Touristic map of the city of Mérida.

A large historical center can be seen, delimited by the walls of the city and crossed by the river Guadiana. In the same way, a concentric growth of the city around the historical center can be identified but we cannot recognize the orthogonal pattern, mentioned in some studies on town planning of Roman times.

Without the particular knowledge of every discipline, it turns out impossible to determine why each city is in the site in which it is located, and what sort of relationship and proportion exists between them; in the same way, it is impossible to identify the road network of the Roman city. There are no links between both cities and any connecting element. Simply one 
city dwells over the other, so that the plots opened in the current mapping seem to be windows on the past. Big windows, that is, but windows that nonetheless give us the feeling of reading history in long sentences that prevent us from contemplating the details that would have allowed a better recreation of those times. Archaeology begins to lose the social nature that must have as a means of educating the city inhabitants on their history to become a catalogue of real estate (at best) or mere remains of them.

\section{Urban plans and laws.}

The first works of archaeology and urban development were carried out in Merida in the mid-seventies, last century. They set the foundations of what must be the interaction between both disciplines to obtain, as result of the works, a whole which shapes the Roman city across the current one. It was a declaration of intentions that acquired more relevance from 1984 onwards, with the transfer of competences in this area from the central government to local government bodies and the creation at the time of the City's Historical-Artistic and Archaeological Trust, supported by the Law 16/1985, of June 25, on the Historical Spanish Heritage. On the other hand, when this trust was created, there was talk about the problem entailed by the fact that there were not enough archeologists. However, having more town planning architects, experts in archaeology, that could add more accuracy to the project as a whole, did not seem a problem.

In 1996, the Consortium of the Monumental HistoricalArtistic and Archaeological City of Merida was born, with mainly an archaeological nature. The Department of Culture, the Council of Culture of the Autonomous Region of Extremadura, the County council of Badajoz and the Town Hall of Merida were part of it.

The Consortium set out the goals of preserving, supporting and appraising the monumental city, as well as the study and assessment of its remains to integrate them in the city but did not address the external collaboration of any architects, either through an architect's association, an independent firm or even university departments involved in the planned tasks.

In fact, there were many studies carried out on the original configuration of the urban development but it was historian Álvaro Corrales Álvarez who indicated that "In spite of abundant archaeological literature on some aspects relative to decoration or morphology, to date, there is no global vision that integrates the study of its architecture, its ornamental programme, its material culture and their insertion in the urban plot, all of them explanatory factors of great interest at present, due to the development that domestic architecture in Hispania has experienced in the last decades".

The local government offers technical personnel to make these works, which are mainly orientated to the review and control of the fulfillment of the initial aims, eliminating the possibility of a continuous follow-up by a committee of experts. In this way we can see how the aims set for the city are fading away due to the absence of interdisciplinary workgroups in which expert town planners support and guarantee the success of the initial approaches.

Thus, we can see that archaeology does not consider urban development as the necessary companion for highlighting the Archaeological Heritage. Instead it considers urban development as the discipline that must shape the punctual findings, omitting, from the start, a global vision that might simplify the study and give an extra value to the different local systems of planning.

\section{CARTAGENA OVER THE FOUNDATIONS OF CARTAGO NovA}

In the southeast end of the Iberian Peninsula in a final enclave, but in an intermediate section of the Vía Augusta, delimited by five hills, one finds the colony of Cartago Nova. Founded on the remains of previous civilizations, its original morphology is the consequence of the complex orography that prevents its access and expansion, facilitating its defense and relevance in the epoch, a product of the mining wealth of the region.

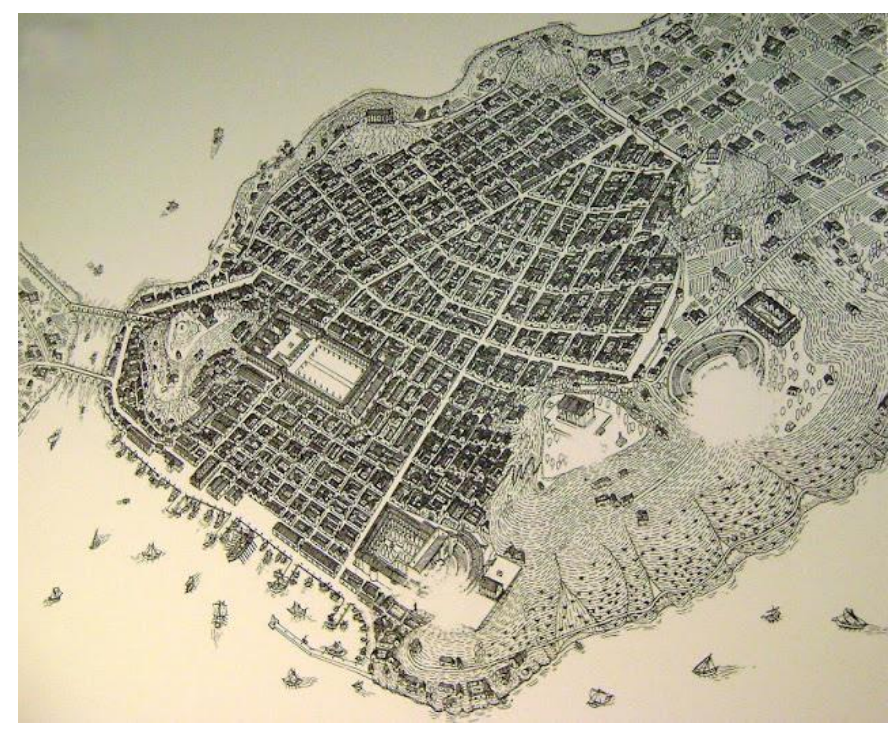

Figure 6. Photo of one of the public posters that represents a map of Roman Cartago Nova, the current Cartagena, with all the buildings characteristic of a city of such importance: walls, temples, forum, amphitheatre, theatre, baths, augusteum, port, markets.

Its five hills, Arx Asdrubalis, current Hill of Molinete, and the Mons Saturnii, Aletis, Vulcanii and Esculapii, the latter identified with the Mount of the Concepción, do not prevent the city from reproducing the basic parameters of Roman town planning: the orthogonal plane, geometric regularity and a great number of public spaces. Its Forum, located in the crossing between the Cardo and the Decumanus, is established in the central part of a city that presents a great variety of public and monumental buildings of the epoch, such as the Theatre, the Amphitheatre, and the Thermal baths.

As a consequence of the decline of the Roman Empire, devastated by other civilizations, the city begins a process of decline, which, after several centuries ends with the practical disappearance of its historical legacy with the exception of isolated elements which, due to their difficult orography, cannot be populated by later civilizations.

It is not until almost the middle of the 20th century, in 1943, when Antonio Beltrán Martínez, Doctor in Philosophy and graduated in Law, assistant of the University of Murcia (1945-49), started highlighting Cartagena's local heritage by formally proposing its Town Hall the establishing of an 
Archaeological Museum that would exhibit the numerous remains recovered in different archaeological excavations in the city. Shortly afterwards, Antonio Beltrán, Emeterio Cuadrado - Assistant Mayor and Town Councilor of Culture in the Town Hall of Cartagena - and Mariano Pascual de Riquelme created a municipal committee with the aim of creating the Museum of Municipal Archaeology, located initially in the headquarters of the Royal Economic Society of Friends of the Country. By means of his Doctoral Thesis "Archaeology, Epigraphy and Numismatics of Cartagena", Antonio Beltrán would become Professor of Archaeology, Epigraphy and Numismatics in Saragossa in 1949. Due to this, he went back to his city of origin leaving a hollow difficult to fill in his professional work.

A few years later, in 1954, Pedro A. San Martín was transferred to the State Finance Delegation in Cartagena as an architect, where he discovered his passion and vocation for archaeology. In the same year of his arrival in the city he was designated local commissioner of Archaeological Excavations. In this capacity, he started numerous projects, interventions and explorations, and continued Antonio Beltrán's works in the defense of the study and conservation of the archaeological remains that appear across the numerous excavations carried out in the Historical Centre, and occupied simultaneously the position of Commissioner for the Archaeological Excavations in the Province between 1945 and 1949.

Miguel Martínez Andreu, archaeologist, wrote: "This new stage that now starts will not be so fruitful from the point of view of research, but will add significant momentum to the field of archaeological restoration/conservation. The vision of architect Pedro A. San Martin allows for the integration of many of the actions carried out in the city with the new construction works, a field where Cartagena can be seen as a pioneer". The recognition of San Martin's works, indicating a new vision about how to preserve our cultural heritage, represents a very different approach from the traditional methods.

In 1967 the Necropolis is discovered in the street Ramón y Cajal, located in the suburbs of the primitive city. This finding leads the Town Hall of the city to initiate the paperwork for the construction of a new space to exhibit the site. The project is entrusted to Pedro A. San Martín, Director of the Municipal Archaeological Museum from 1956 and an emblematic figure in the transformation experienced by the city in the following years, although this Museum would not be not inaugurated until 1987.

\section{A. Archaeological remains}

Among its numerous Roman remains, the recently restored Roman theatre of Carthago Nova stands out and is one of the landmarks of the city. Its building works started at the end of the 2 nd century BC. Other Roman remains could be found on several buildings and centers for interpretation, including the Roman colonnade, the House of Fortune, the Decumanus and the Augusteum. The Torre Ciega was built by the Romans for burials rituals, and it formed part of the Necropolis.

The Roman Amphitheatre (1st century AD) lies where the now abandoned Bullring was built, but only some of the surrounding walls and part of the rooms under the stands are still visible.

\section{B. Overlapped cities}

One of the most important key findings that archaeologists have found in Cartagena are the remains of road paths. By studying in depth their morphology it can be deduced how urban plans must have been in the Roman period and through them a model of the superposition of both cities can be made.

In this way the main axis and streets of the old city can be reflected in the present one, but we cannot discern the orthogonal axis that every Roman city is meant to have. Therefore, we can conclude that the morphology in Cartagena could have affected the way in which its urban planning was formulated.

We cannot forget that Cartagena had a different and special morphology and geometry due to a small lake that was located in the northern area of the city. Probably, due to this, all buildings had to be concentrated in the higher area of the city.

The lake disappeared during the last centuries and the main consequence was the spread of the city towards the old suburbs and Roman Necropolis, which meant that the newly developed areas lost their relationship with the city centre.

All these discoveries allow us to understand the old city, how it worked and how the main buildings were linked.

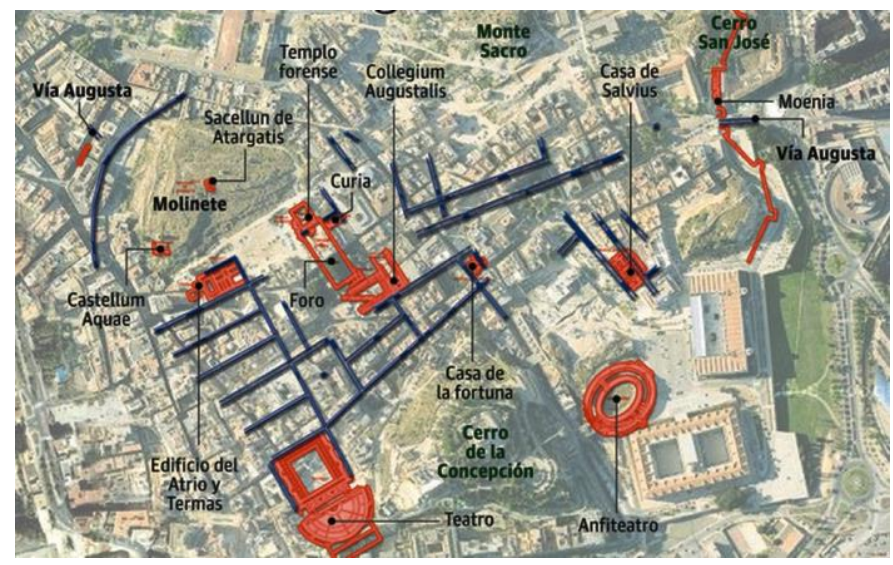

Figure 7. Overlapping of urban plots in the city of Cartagena.

Figure 7 shows the location of the main Roman buildings, i.e. the Roman theatre of Carthago Nova, the Roman Amphitheatre, the Roman colonnade, the House of Fortune, the Decumanus and the Augusteum and their positions and spaces in the new city.

\section{Urban plans and laws}

As the Urban Development Department of the city recognizes in the introduction of its Urban Plan in 2012, "The urban development situation in Cartagena was really chaotic. Although the first General Plan of Cartagena, drafted by the Ministry of Housing, had been approved in 1961, the development of the city paid no attention whatsoever to the Plan, both in this decade and in the following one. In 1976, the Ministry of Housing approved a modification of the General Plan, which regulates the heights and the uses of buildings in the old part of town and in the area of the enlargement, and classified as urban soil the settlements of the interior and the beaches, for their development by means of PERI. Furthermore, in 1977, the "General Plan of Beaches", which regulates the coastal soil, was introduced and passed 
unopposed. Thus, Cartagena became a town regulated by two general, contradictory Plans".

As in other cities, the Law 16/1985, of June 25, on the Historical Spanish Heritage, can be considered as a milestone in local town planning. However in the case of Cartagena it is particularly relevant, since the approval of this Law coincided with the drafting of the General Plan of Urban Regulation of Cartagena (1987) in which Pedro San Martín, as an architect and in a personal capacity, aimed at preserving the Historical Heritage by means of proposing a more exhaustive catalogue than the one included in new Law for the new General Plan. This situation generated a confrontation almost at personal level with the Town Hall, due to the determination that he perceived in the Town Hall to approve a General Plan that, in his opinion, was contrary to the environmental interest. $\mathrm{He}$ requested the inclusion in the General Plan Protection Catalogue of up to four protection degrees, out of which three were finally approved. The consequence of this delay was the impossibility of incorporating the PERI (Special Plans of Interior Reform) into the structure of the finally approved document.

The solution raised for the previous problem established the following: "In the area of the Historical Set of Cartagena the General Plan has the consideration of a Special Plan of Arrangement and Protection (P.E.O.P.), since it contains the rules for the protection of the Archaeological Heritage, as well as the historical-artistic heritage, by means of the inclusion of aesthetic rules and the Catalogue of protected buildings. These dispositions are replaced by the Special Plan of Arrangement and Protection of the Historical Set, P.E.O.P. C.H, partially approved by Plenary Agreement of March 3, 2005, and in its entirety by the Agreement of November 7, 2005, having taking notice of the Recast Text by means of the Decree of the Vicepresident of the Management Department of May 8, 2006".

Solutions to isolated problems and solutions to global problems were perceived, so that the proposed legislation tried to solve the issues previously raised but did not define with clarity the future scenarios of coexistence between archaeology and urban development.

\section{The role of Pedro A. San Martin in Cartagena}

Being aware of the issues regarding the coexistence of superimposed cities and knowing the economic implications for the real-estate sector, Pedro San Martín considered that making large expropriations could lead to the deterioration of the city and deter potential investors due to the difficulties of initiating real-estate promotions. As a true expert of archeological discoveries in the city, and convinced of the potential that this particular one might have, he decided to apply to his projects new building techniques that allowed for the preservation of all archaeological findings while reducing the economic impact on the building companies.

P. San Martín then considered preserving the findings in the basements and ground floors of the buildings, so that in a continuous way, it would be possible to visit the remains of the Roman city under the current urban development: two linked while distinct cities arranged in different strata. It would mean a new way of understanding and traversing a city where its inhabitants or visitors could experience ways of living from 2000 years ago. All these methods were applied in his project of the Roman site in Duque Street in Cartagena in 1971. Later, he had the chance to follow the same modus operandi in the Byzantine Walls in 1983. In fact, we can find a similar plan of action in all projects built in the city center of Cartagena during this period. It is a new concept which exposes history through the foundations of new projects.

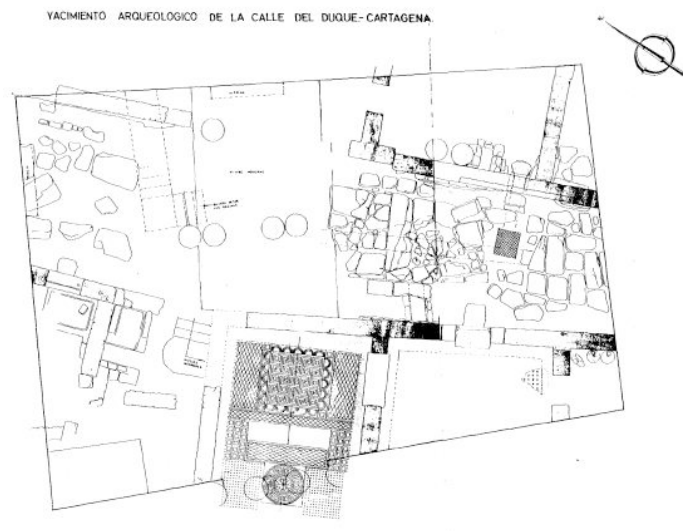

Figure 8. Archaeologic remains in Duque Strret in the city of Cartagena.

In 1988 Pedro A. San Martin was entrusted with the project for the construction of the Regional Centre of Crafts in a lot located in the Square of the Countess of Peralta. After the first findings during the execution of the works, San Martín began to understand the importance of the discovery under way. Therefore, he proposed buying the bordering lot to the Council of the Autonomous Government in order to check the initial hypotheses. This situation generated a great commotion and due to his insistent requests, the government bodies acceded to the acquisition. It was then when the findings began to receive special relevance and became a discovery.

Over time, the explorations continued and in 1996 an agreement of collaboration was signed between the Town Hall of Cartagena, the Autonomous Region of Murcia, and the Cajamurcia Foundation that allowed for the continuation of the works until 2003, the year when the Roman Theatre of Cartagena Foundation was created in order to continue with the works of excavation and exhibition. By then, P.A. San Martín was already eighty two years old and his role in the shaping of the findings became less important. It was then when a team of well-trained and experienced archeologists took over his work. But they did not know in depth the urban development discipline and focused mainly on looking for new sites and highlighting them without sharing the considerations that an archeologist, architect and town planner like Pedro A. San Martin had raised in a rational way throughout his professional career.

\section{CONCLUSION}

The main findings of this research that we can conclude are:

Having considered the precedents and all the actions carried out in some cities of the Spanish territory, the Law 16/1985, of June 25, on the Historical Spanish Heritage constitutes the cornerstone in local town development, allowing deeper awareness regarding exhibition and highlighting works. 
The proposals to link archaeological remains in the new urban plans of the cities must be carried out by expert urban planners and not only by archaeologists and politicians in order to avoid the disappearance of the node which links different ages in the cities, as we have seen in Merida and Tarragona. Urban architects are qualified to establish urban basis in order to get a rational development of the cities including archaeological remains as Cultural Heritage.

The fact of finding an urban architect involved in archaeological discoveries (as Pedro San Martín) is a special situation that we have only seen in Cartagena. In fact, this could be the main reason for not having found overlapping maps or proposals in the studies of other similar cities in Spain.

The images included in this article show different disperse spots of highlighted spaces and the urban routes that were used to link them, separated from the current fabric of the historical center of the city. By means of the proposed system of exhibition of the Heritage - which delimits clearly the surface of the different archaeological sites - physical barriers are created that only allow one to traverse and understand parts of the Roman city and not its unitary structure.

All the efforts made by Pedro San Martín during the second half of the 20th century have not been continued in the context of Cartagena's urban development. This, in turn, has triggered a series of actions aimed at enriching the Historical-Artistic Heritage of the city while avoiding the preservation of how that Heritage referred to the ancient urban fabric and losing a unique pioneering opportunity in the recovery of historical plots.

\section{REFERENCES}

[1] "Archaeology of modern cities superimposed on old ones. Zaragoza 1983" Zaragoza, 1983, Ministry of Culture.

[2] European seminar of Management of Historical City Centers. Granada, On November 8,9 and 10,2000

[3] S. Myrvoll "The city inside the city: the integration of the patrimonial management in the modern urban development". European seminar of Management of Historical City Centers. Granada, On November 8,9 and 10,2000

[4] P. Mateos Cruz: "The patrimonial management in a city superposed to an archaeological deposit: the model of Merida" European Seminar of Management of Historical City Centers. Granada, On November 8,9 and $10,2000$.

[5] M. Asensio. L. Colomer. J. Ruiz. N. Sanz. "APPEAR Project: The city and the valoritzacion of the European archaeological heritage". III International Congress about Exhibition of Archaeological Sites pp. 225228. De la excavación al público. Procesos de decisión y creación de nuevos recursos. Zaragoza, 15, 16, 17 y 18 de noviembre de 2004. ISBN 8069-392-4.

[6] F. Amores Carredano. D. González Acuña. A. Jiménez Sancho. The valoritzacion of the archaeological remains of the incarnation and the emergence of a new heritage stage in the city of Seville. III International Congress about Exhibition of Archaeological Sites pp. 235-238. Zaragoza. ISBN 8069-392-4. 2004

[7] V. Barba Colmenero. F. Alcalá Lirio. M. Navarro Pérez. F. Arias de Haro. Prospects for the creation of new spaces Museum in the historic public places. III International Congress about Exhibition of Archaeological Sites pp. 25-29. Zaragoza. ISBN 8069-392-4. 2004
[8] C. Aguarod. R. Erice. A. Mostalac. Caesaraugusta, four themes for a single urban context. III International Congress about Exhibition of Archaeological Sites pp. 137-143. Zaragoza. ISBN 8069-392-4. 2004

[9] J.M. Esteban González, A. Muñoz Vicente, F.J. Blanco Jiménez. Brief history and criteria of intervention in the urban area of the Roman theatre of Cadiz. Roman theatres of Roman Spain pp. 141-156. Notebooks of Roman Architecture, Vol 2. 1993.

[10] Ruiz de Arbulo, Joaquín, Mar, Ricardo, 1999: Archaeology and town planning in Tarragona. Tradition and current reality, to recover the urban memory. The Archaeology in the rehabilitation of the historical cities, URV / Fund. La Caixa, Tarragona. 1997.

[11] Areste Bages, Jaume. The growth of Tarragona in the 19th century Of the New Population of the Port to the Plan of Widening. Tarragona: Publicacions del Col.legi d'Aparelladors i Arquitectes Tècnics de Tarragona i de 1'Excm. Ajuntament, 1982. $240 \mathrm{p}$.

[12] Blázquez Martínez, José María. Religion and Urbanism in Emeritus August. Antigua. History and Archaeology of the civilizations. Spanish file of Archaeology, núm. 55 (1982), pp. 89-106. Another ed.: Blázquez Martínez, Jose Maria, Religions in the ancient Spain, Madrid, Chair, 1991, pp. 263-283. Virtual library Miguel de Cervantes. 1991

[13] Corrales Álvarez, Álvaro. Religion and Urbanism in Emeritus August. Antigua. History and Archaeology of the civilizations. Spanish file of Archaeology, núm. 55 (1982), pp. 89-106. Another ed.: Blázquez Martínez, Jose Maria, Religions in the ancient Spain, Madrid, Chair, pp. 263-283. Library Virtua 1 Miguel de Cervantes. 1991

\section{AUTHOR'S PROFILE}

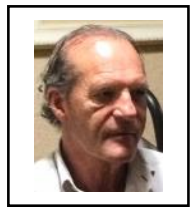

Dr. Francisco Segado Vázquez, is a Professor in Cartagena Technical School of Architecture. He was graduated as an architect in Valencia in 1985 and in 1995 obtained his post-Graduated.

Nowadays, he is President of the Post-Graduate Commission, at Polytechnic University (Cartagena). His contribution "Urban integration of high speed train" was published in GSTF JET in 2014.

Prof. Vázquez attended the 2nd and $3^{\text {rd }}$ Annual International Conference on Architecture and Civil Engineering (ACE 2014-2015) Singapore, the $3^{\text {rd }}$ International Congress REUSO 2015, Valencia, Spain and $10^{\text {th }}$ International Conference on Urban Regeneration and Sustainability (SUSTAINABLE CITY 2015) Medellín, Colombia.

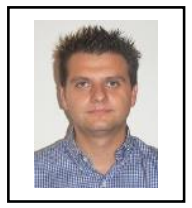

José Manuel Maciá Albendín, is a post-Graduate student in Cartagena Technical School of Architecture. Graduated in 2002 as an architect, in Valencia, he obtained a Master in Business Administration by EEN (2013, Spain).

Since 2002, he has worked as an architect and as Technology Teacher, as secondary education teacher in Cartagena and Associate Professor at European Business School.

$\mathrm{Mr}$ Maciá, attended the $3^{\text {rd }}$ Annual International Conference on Architecture and Civil Engineering (ACE 2015) Singapore, the $3^{\text {rd }}$ International Congress REUSO 2015, Valencia, Spain and $10^{\text {th }}$ International Conference on Urban Regeneration and Sustainability (SUSTAINABLE CITY 2015) Medellín, Colombia.

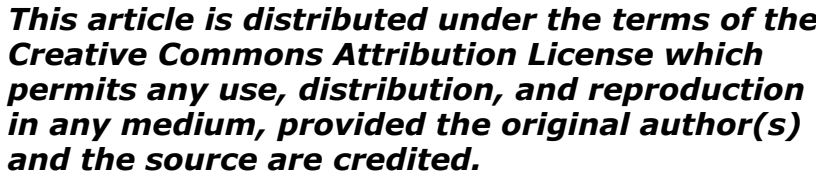

